
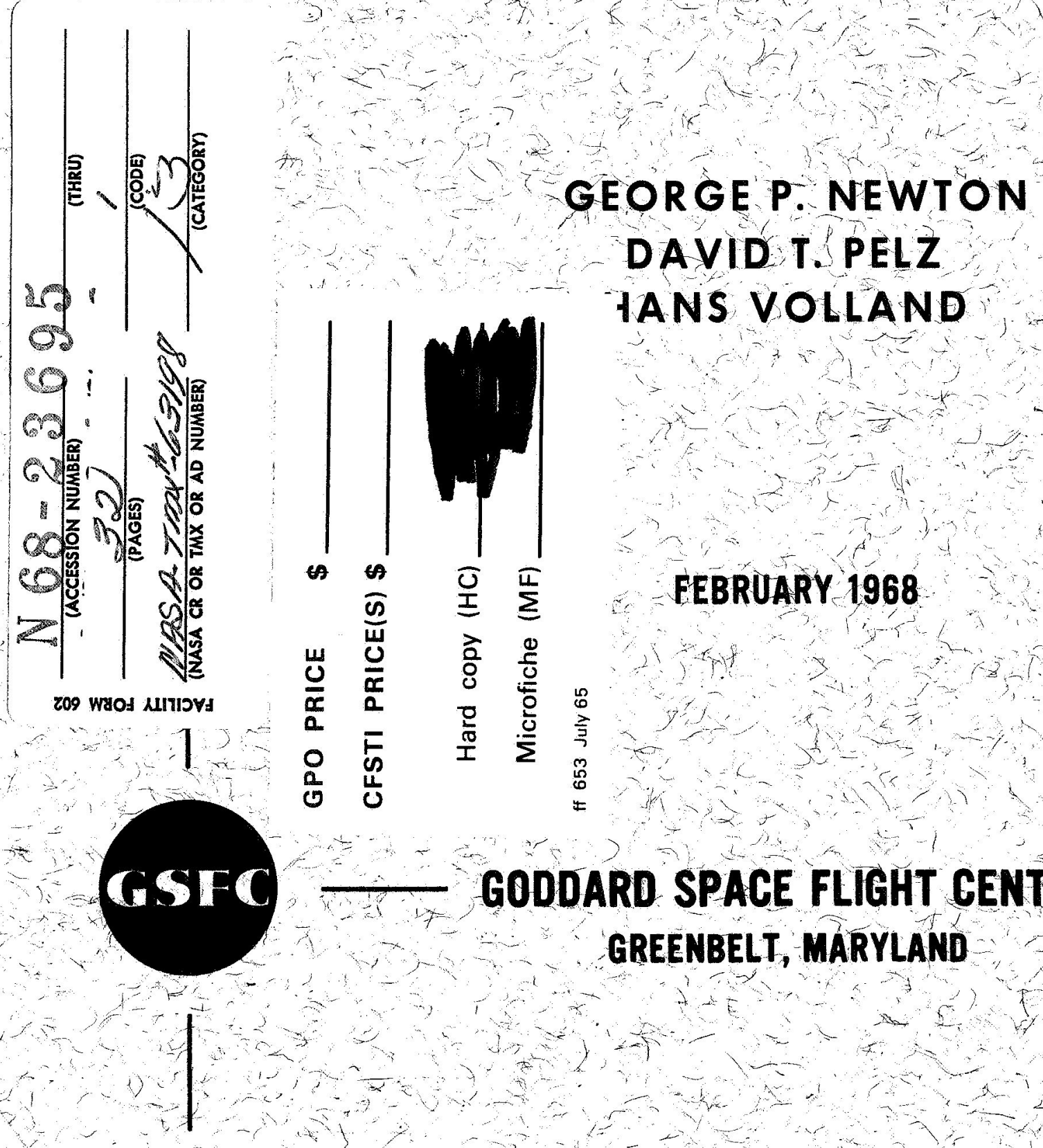

GODDARD SPACE FLIGHT CENTER GREENBELT, MARYLAND 


\section{DIRECT, IN SITU MEASUREMENTS OF WAVE PROPAGATION \\ IN THE NEUTRAL THERMOSPHERE}

by

Aeronomy Branch

Goddard Space Flight Center

Greenbelt, Maryland

*National Academy of Sciences - National Research Council Senior Research Associate, on leave from Bonn University. 


\title{
DIRECT, IN SITU MEASUREMENTS OF WAVE PROPAGATION \\ IN THE NEUTRAL THERMOSPHERE
}

by

George P. Newton, David T. Pelz, and Hans Volland

\begin{abstract}
The density gauges on the Explorer 32 satellite have measured local variations in the atmospheric density which confirm that waves propagate in the neutral atmosphere. The waves were observed in the northern hemisphere over the altitude range from $286 \mathrm{~km}$ (satellite perigee) to at least $510 \mathrm{~km}$. The waves are most prevalent at the higher latitudes near the auroral zone (orbit inclination is $65^{\circ}$ ) and were observed most frequently in the late evening and early morning hours, but were not limited to these latitudes and times. The virtual vertical half-wavelengths of the waves increase with altitude from $1 \mathrm{~km}$ at 286 $\mathrm{km}$ altitude to $70 \mathrm{~km}$ at $510 \mathrm{~km}$ altitude. Four integrally related wavelengths have been observed, a "fundamental" and the second, third, and fourth harmonics. The wave half-amplitudes range from the limit of detectability to the largest observed of $50 \%$ of the smoothed density profile value. These waves are identified as free internal gravity waves propagating predominately north-south, or southnorth, with horizontal wavelengths between 130 and $520 \mathrm{~km}$ and periods between 10 and $100 \mathrm{~min}$. This interpretation is consistent with observations of large scale traveling ionospheric disturbances by Thome and Georges.
\end{abstract}


DIRECT, IN SITU MEASUREMENTS OF WAVE PROPAGATION

IN THE NEUTRAL THERMOSPHERE

by

George P. Newton, David T. Pelz, and Hans Volland

\section{INTRODUCTION}

It has been suggested by Hines (1960) that traveling ionospheric disturbances are caused by waves in the neutral air within the thermosphere. Previously these waves were observed only indirectly by the response of the ionospheric F-region to the neutral air disturbance (Heisler, 1967):

This paper presents the first direct observations of neutral wave structure in the thermosphere and describes in greater detail than an earlier paper (Newton, et al., 1967) the characteristics of the waves. These results were obtained by the atmospheric density experiment on the Explorer 32 satellite. Additional atmospheric density information is available from the experiment and will be presented in a later report.

\section{INSTRUMENTATION}

Satellite

The Explorer 32 satellite, a second generation aeronomy satellite, was launched on 25 May, 1966 into a $64.6^{\circ}$ orbit with a perigee of $286 \mathrm{~km}$ and an initial apogee of $2700 \mathrm{~km}$. The satellite basic structure was a vacuumsealed sphere, approximately $88 \mathrm{~cm}$ in diameter. The system had an active 
life of approximately 10 months during which 8304 data producing turn-on's, each of four minutes duration, were accomplished. A magnetic control system maintained the satellite spin-axis usually within five degrees of normal to the orbit plane and the spin rate at $1 / 2$ rps. An artists' conception of the satellite is shown in Figure 1.

The scientific instrumentation included in the satellite was:

1. Two neutral particle mass spectrometers, one mounted on the satellite equator and one mounted on the spin axis;

2. One ion mass spectrometer mounted on the satellite equator;

3. Two electrostatic Langmuir probes mounted on the satellite equator;

4. Three magnetron type density gauges, two gauges mounted on the equator and one mounted $55^{\circ}$ off the equator.

The Satellite System was designed to permit turn on of the experiments and transmission or recording of data for approximately four minute intervals. Most of the experimental data were obtained in real time by the STADAN ground stations, although considerable data were obtained at "remote" locations using the satellite tape recorder.

\section{Density Gauges}

The atmospheric density experiment used three cold cathode magnetron gauges of two types to measure the density. One gauge type (NRC-528) was 
identical to the cold cathode gauges flown on the Explorer 17 satellite. The second gauge type (GCA-R5) differed in materials and geometry. Both gauges are shown in cross section in Figure 2. A description of the principles of magnetron gauge operation is given by Redhead (1959). Descriptions of the flight gauges and their laboratory responses have been reported (Newton, et al., 1963, Pelz and Newton, 1967). One gauge of each type was mounted on the satellite equator and the off-equatorial gauge was a GCA-R5. Each of the three gauge systems had an individual high voltage power supply and an electrometer. The equatorial GCA-R5 gauge had a linear, range switching electrometer which provided high resolution-current measurements $(>98 \%$ resolution) and the other two gauges had logarithmic electrometers. All electrometers were calibrated once each satellite turn-on. The gauges were calibrated, sealed and launched under vacuum and opened on command when the satellite was in orbit. All instrumentation operated as intended in orbit.

\section{RESULTS}

The technique of using density gauges to perform atmospheric density measurements has been given (Newton, et al., 1965, Schultz, et al., 1948, Havens, et al., 1952, Horowitz and Kleitman, 1953). Measured atmospheric density is proportional to the pressure change measured by the gauges during the rotation of the satellite about its spin axis. Thus the time resolution of the density measurements by one gauge was two seconds (the spin period) corresponding to a spatial resolution along the satellite orbit of approximately $16 \mathrm{~km}$. The wave 
structure characteristics which were measured during a satellite turn-on are largely independent of the absolute calibration of the gauges and are influenced primarily by the relative precision of the gauge measurements which is believed to be better than $2 \%$. Figure 3 shows a typical "smooth" atmospheric density profile. The line in the figure is determined by the least squares fit to the data of an exponential density dependence on altitude. It should be pointed out that the satellite was simultaneously changing local time, latitude and altitude during the pass. The changes in these parameters during a pass depend upon the location of the satellite in its orbit, however, typical maximum observed changes in local time and latitude during a turn-on are approximately 2 hours and 20 degrees respectively.

Figure 4 shows the maximum and minimum "pressures" versus time measured by the equatorial GCA gauge each satellite spin for turn-on 924 . The local variations in the maximum pressure indicate structure in the atmospheric density distribution. During this pass the satellite was increasing altitude as evidenced by the decreasing gauge maximum and minimum pressure.

Figure 5 shows the same data as in Figure 4, displayed as atmospheric density versus altitude. The local density structure is quite apparent and was observed simultaneously by the three independent gauge systems. The line in the figure again represents a least squares fit to the data of an exponential dependence of density on altitude. Complex wave structure is visible in Figure 5 and suggests that there might have been a superposition of waves of different frequencies occurring. 
Figure 6 shows the atmospheric density profile measured on turn-on 1067 at altitudes near $400 \mathrm{~km}$.

Figure 7 shows the density profile measured at perigee during turn-on 637 . The data start at $291 \mathrm{~km}$ altitude and proceed through perigee and back to $296 \mathrm{~km}$ altitude. The wave structure is apparent on both the increasing and decreasing altitude portions of the pass.

Figure 8 shows the apparent vertical half-wavelength versus altitude determined from the passes listed in Tables 1 and 2. The lines are discussed in the interpretation section. The apparent half-wavelength has been plotted at the mean altitude of the wave half-cycle under consideration. The data have local times between 2100 and 0500 hours. The circles represent the shortest apparent half-wavelengths discernable during any turn-on and are usually easily measured. The triangles represent the largest apparent half-wavelengths discernable during a turn-on when complex wave structure is present. The accuracy of the smaller half-wavelength determination is believed to be generally $\pm 20 \%$. The larger apparent half-wavelengths are more subjective in their determinations since some visual smoothing is performed. The two sizes of half-wavelengths appear to be integrally related, that is the smaller half-wavelengths usually correspond to harmonics of the larger half-wavelengths. The data have surprisingly small scatter, indicating that only a limited range of horizontal wavelengths were observed (see discussion section). 
The geographic locations of the passes where local structure was observed are shown in Figure 9, where the subsatellite points corresponding to the start and end data used from each satellite turn-on have been plotted and connected with a straight line. For the indicated days when wave structure was observed all data analyzed for that day are shown. It appears that the occurrence of the local structure is limited to latitudes greater than $20^{\circ}$ and that the phenomena occurs more frequently near the auroral zone.

The half-amplitudes of the density structure variations have been measured with respect to a line representing an exponential dependence of density on altitude which has been fitted to the data by the method of least squares. The halfamplitudes vary from the limit of detectability to the largest observed of $50 \%$. The most commonly observed half-amplitudes are 10-20\%. At this time there is no consistent pattern apparent between the wave half-amplitudes and altitude, since the wave half-amplitude sometimes appears to be attenuated as the altitude increases, although constant amplitude waves are observed most often. There is some indication that the density is greater than usual during times when the local structure is apparent. The wave-like density structure is observed both on days indicated as geomagnetically disturbed and undisturbed. However, the wavelike density structure is observed predominantly during the late evening and early morning hours. 


\section{INTERPRETATION}

Traveling ionospheric disturbances have been observed which propagate with oblique phase planes and a bending of the phase planes toward the vertical with increasing height (Thome, 1964; George, 1967). Georges (1967), from HF-doppler studies, also observed vertically upward moving waves with periods of the order of 3 min which he interprets as acoustic waves. Hines (1967) has interpreted Thomes's measurements as resulting from free internal gravity waves which are refracted with height by the influence of heat conductivity within the thermosphere. Thus, two wave modes are suggested that could propagate in the neutral thermosphere.

In this section we present first the conclusions drawn from the observed wave amplitude behavior. Second, we discuss the effect of the satellite velocity on the observed wavelengths. Third, we present observations of the relative locations of the observed wave phase planes in space and time, at the satellite perigee. Fourth, we discuss the implications of the preceeding three discussions on the type of wave mode observed and reach the conclusion that the observed wave structure is caused by internal gravity waves.

1) Amplitude.

Our experimental observations show that the amplitudes of the waves are nearly constant with height. From the discussion of the amplitude behavior of gravity and acoustic waves in the Appendix we conclude that the waves must propagate upward. Heat conduction wave amplitudes are attenuated more 
strongly with altitude than gravity or acoustic waves and hence heat conduction waves can be excluded as the origin of our observed wave like structure. Thus, only gravity or acoustic waves remain as possible causes of the observed structure.

2) The satellite velocity influence.

For a theoretical consideration we assume that these waves are harmonic waves with angular frequency $\omega$ extending horizontally to distances of several thousand $\mathrm{km}$ with constant horizontal wave number $\mathrm{k}_{\mathrm{x}}$. Assuming the validity of ray optics the phase of one of these waves is given by

$$
\Phi(\mathrm{x}, \mathrm{z}, \mathrm{t})=\omega\left(\mathrm{t}-\mathrm{t}_{\mathrm{I}}\right)-\mathrm{k}_{\mathrm{x}}\left(\mathrm{x}-\mathrm{x}_{\mathrm{I}}\right)-\int_{\mathrm{z}_{\mathrm{I}}}^{\mathrm{z}} \operatorname{Real}\left(\mathrm{k}_{\mathrm{z}}\right) \mathrm{d} \xi
$$

where $\mathrm{x}$ is the horizontal direction of wave propagation, $\mathrm{z}$ is the altitude, $\mathrm{t}$ the time and Real $\left(k_{z}\right)$ is the real part of the (generally complex) vertical wave number $\mathrm{k}_{\mathrm{z}}$ of the dissipative wave within the thermosphere in which heat conduction plays a dominant role. $\left(x_{I}, z_{I}, t_{I}\right)$ is an arbitrary initial point in our coordinate system. For convenience we select this point to be at the perigee of the satellite orbit. The projection of the satellite path into the $(x, z)-p l a n e$ leads to the following equations of motion:

$$
\begin{aligned}
& \left(x-x_{I}\right)=V_{x}\left(t-t_{I}\right) \\
& \left(z-z_{I}\right)=\dot{V}_{z}(z)\left(t-t_{I}\right)
\end{aligned}
$$


where $V_{x}$ and $V_{z}(z)$ are the horizontal and vertical satellite velocity components respectively. The $\mathrm{y}$-component of the satellite motion does not influence the observed wave structure in our idealized model. The horizontal component of the satellite velocity is nearly constant and does not exceed the total velocity $\mathrm{V}$ :

$$
\mathrm{V}_{\mathrm{x}}=\text { const } \leqq \mathrm{V}=8.3 \mathrm{~km} / \mathrm{sec}
$$

The vertical component can be approximated near perigee by the analytic function

$$
V_{z}=\frac{\sqrt{\left(z-z_{I}\right)}}{A} \operatorname{sign}\left(t-t_{I}\right) \mathrm{km} / \mathrm{sec}
$$

with

$$
A=19.8 \mathrm{sec} / \mathrm{km}^{1 / 2} .
$$

We are interested in the vertical distance between two extrema of the wave structure along the satellite path. We find this apparent vertical half wavelength, $\lambda_{z}^{\prime}$, from the condition

$$
\Phi\left(z+\frac{\lambda_{z}^{\prime}}{4}\right)-\Phi\left(z-\frac{\lambda_{z}^{\prime}}{4}\right)=\pi
$$

Eliminating $\mathrm{x}$ and $\mathrm{t}$ in Equation 1 by using Equation 2 we obtain

$$
\omega_{\text {eff }}\left\{\frac{z+\lambda_{z}^{\prime} / 4-z_{I}}{V_{z}\left(z+\lambda_{z}^{\prime} / 4\right)}-\frac{z-\lambda_{z}^{\prime} / 4-z_{I}}{V_{z}\left(z-\lambda_{z}^{\prime} / 4\right)}\right\}-\int_{z-\lambda_{z}^{\prime} / 4}^{z+\lambda_{z}^{\prime} / 4} \operatorname{Real}\left(k_{z}\right) d \xi=\pi
$$


with

$$
\omega_{\text {eff }}=\omega-k_{x} v_{x}
$$

and $\mathrm{V}_{\mathrm{z}}$ from Equation 3. From Equation 4 it is possible to calculate the apparent half-wavelength as a function of altitude. Equation 4 shows that the real vertical half -wavelength, which is defined as

$$
\int_{z-\lambda_{z} / 4}^{z+\lambda_{z} / 4} \operatorname{Real}\left(\mathrm{k}_{z}\right) \mathrm{d} \xi=\pi
$$

is modified by an effect due to the horizontal motion of the satellite (the first term in Equation 4). This horizontal motion effect can lead to a negative $\omega_{\mathrm{eff}}$, if $\omega<\mathrm{k}_{\mathrm{x}} \mathrm{V}_{\mathrm{x}}$ and therefore to an apparent reversal of the direction of the observed phase propagation.

The influence of the satellite motion on the apparent half-wavelength variation with altitude can be considered by using Equation (4) and neglecting the vertical phase integral. For a given value of $\omega_{\text {ef } f}$ the vertical half-wavelength may be calculated. The solid lines in Figure 8 represent the results of these calculations for values of $\omega_{\text {eff }}$ of 0.1 (line 1), 0.2 (line 2) 0.3 (line 3) and 0.4 (line 4) $\mathrm{rad} / \mathrm{sec}$. It is seen that the altitudinal variation of the apparent halfwavelength can, for these values of $\omega_{\text {ef } f}$, be explained solely by the variation of the vertical component of the satellite velocity with altitude. In Figure 8 it appears that the fourth harmonic is the greatest frequency observed. Apparently 
the observed half-wavelengths for altitudes above $400 \mathrm{~km}$. in reality belong to the fundamental half-wavelength. These results imply that the contribution of the phase integral in Equation 4 must be small. We thus have

$$
0.1 \leq \omega_{\text {eff }} \leq 0.4
$$

\section{3) Relative Phase Plane Locations.}

Figure 10 shows the satellite versus time for the same data of Figure 7 (turn-on 637). The location of the observed points of maximum and minimum phase of the wave are also indicated. The lines indicating planes of constant phase will be discussed later. The numbers in Figures 7 and 10 identify the same extrema in the density structure. However, in Figure 10 the uncertainty in the atltitude-time location of the extrema phase points are estimated by the dark bands on the satellite orbit. As can be seen in Figure 10, the observations obtained on the decreasing altitude portion of the orbit are approximately $1000 \mathrm{~km}$ distance from the observations obtained on the increasing altitude part of the orbit. It should be noticed that amplitude and time spacing of the waves are approximately constant over the large horizontal extent of the observed structure. The time interval of 16 seconds between adjacent extrema in Figure 10 gives an apparent angular frequency of approximately $0.2 \mathrm{rad} / \mathrm{sec}$.

4) Observed Wave Mode.

Two wave modes are considered as possible causes of the observed structure, acoustic and gravity waves. We will now consider each type separately. 
a) Acoustic waves.

Contrary to the case of gravity waves, the thermosphere is nearly isotropic with respect to acoustic waves. Acoustic waves originating in the lower atmosphere are expected to propagate mainly vertically because obliquely propagating waves are attenuated more heavily than vertically propagating waves by the inverse distance dependence of the wave amplitude. This is in agreement with the measurements of Georges (1967) who observed the horizontal extent of coherent acoustic waves to be only a few hundred kilometers. There exists no observational evidence of horizontally traveling ionospheric disturbances in the acoustic frequency range $\left(\omega>10^{-2} \mathrm{rad} / \mathrm{sec}\right.$. $)$.

The results of Figure 10 , which shows a wave-like structure with horizontal extent of more than $1500 \mathrm{~km}$, contradict an acoustic type wave interpretation. Moreover, for the equal horizontal spacing of approximately 16 seconds between adjacent extrema in Figure 10, and assuming $\mathrm{k}_{\mathrm{x}}=0$, one obtains a frequency of $2 \times 10^{-1} \mathrm{sec}^{-1}$. This frequency gives a vertical half-wavelength of $10 \mathrm{~km}$ for an acoustic speed of $0.7 \mathrm{~km} / \mathrm{sec}$. It is impossible to describe the extrema locations shown in Figure 10 by phase planes of constant frequency equally spaced in time with such small vertical wavelengths. Further, for small wavelengths the phase integral of Equation 4 would dominate the first term and a large difference in the observed virtual, vertical half-wavelengths between decreasing and increasing altitude satellite paths would be expected but is not observed. For these reasons we exclude acoustic waves as the origin of our observed wave structure. 
b) Gravity waves.

For gravity waves at these altitudes we have $\omega \ll \omega_{\text {eff }}$ and hence the apparent frequency is due to the horizontal motion of the satellite:

$$
\begin{aligned}
& \omega_{\text {eff }} \approx\left|\mathrm{k}_{\mathrm{x}} \mathrm{v}_{\mathrm{x}}\right| \\
& \therefore \lambda_{\mathrm{x}}=\frac{2 \pi \mathrm{v}_{\mathrm{x}}}{\omega_{\text {eff }}}
\end{aligned}
$$

For $\omega_{\text {eff }}=0.1$

$$
\lambda_{\mathrm{x}}=62.8 \mathrm{v}_{\mathrm{x}}
$$

Therefore maximum $\lambda_{\mathrm{x}} \approx(62.8)(8.3) \approx 520 \mathrm{~km}$.

For $\omega_{\text {eff }}=0.4$

$$
\operatorname{maximum} \lambda_{\mathrm{x}} \approx 130 \mathrm{~km}
$$

The maximum values of the horizontal wavelengths correspond to the wave propagating in or opposite to the horizontal direction of motion of the satellite and hence predominently south-to-north or north-to-south. Georges (1967) and Thome (1964) report the predominent propagation direction of the waves they observe as north to south. This scale of horizontal wavelength also explains the nearly constant amplitude of the waves at higher altitudes since a small attenuation factor is expected for these wavelengths near $500 \mathrm{~km}$ (Volland, 1968).

The large horizontal extent of the waves evidenced in Figure 10 is then quite consistent with the expected behavior of gravity waves. However, because the 
magnitudes of the expected vertical wavelengths are large compared to the coordinate scales of Figure 10, the planes of constant phase in Figure 10 are nearly vertical and would be equally spaced in time. Thus the slope of the phase planes in Figure 10 cannot be determined from the points of extreme phase, and it is not possible to determine the real frequency of the waves from our observations. From measurements of traveling ionospheric disturbances a frequency range between $10^{-3}<\omega<10^{-2} \mathrm{sec}^{-1}$ is expected. As seen previously, the mean horizontal time spacing of the adjacent extrema in Figure 10 is approximately $16 \mathrm{sec}$ which corresponds to the second harmonic of $\omega_{\text {eff }}=0.2 \mathrm{sec}^{-1}$. The vertical lines in Figure 10 have been drawn equally spaced by 16 sec intervals and are in agreement with the data.

Equation 4 was used to calculate the apparent vertical half-wavelengths including the phase integral contribution for a horizontal wavelength of $520 \mathrm{~km}$. and an angular frequency of $10^{-3} \mathrm{rad} / \mathrm{sec}$ (period approximately $\left.105 \mathrm{~min}.\right)$. Equation A1 from the Appendix was used to determine the integrand of Equation 4 , and an $\omega_{\text {ef } f}$ of $0.1 \mathrm{rad} / \mathrm{sec}$ was used. The results of this calculation are shown in Figure 8 as the dashed lines marked $1^{\prime}$ and $1^{\prime \prime}$. The line $1^{\prime}$ was calculated for the satellite ascending in altitude and the line $1^{\prime \prime}$ was calculated for the satellite descending in altitude. It is seen that the vertical variation of the wave number and the vertical direction of motion of the satellite have little effect on the results from Equation 4. This is true not only for this particular case, but for gravity waves generally with frequencies $10^{-4}<\omega<10^{-2}$. Thus, the 
expected characteristics of gravity waves are entirely consistent with our observations.

The real vertical wavelength is defined by Equation 5 . Using Equation A1 of the Appendix with Equation 5 the vertical half-wavelength, $\lambda_{z} / 2$, was calculated. Also calculated were the angles between the vertical and the directions of phase and energy propagation direction, $\vartheta_{\mathrm{ph}}$ and $\vartheta_{\mathrm{en}}$ respectively, from equations $\mathrm{A} 5$ and $\mathrm{A} 6$ respectively, and the attenuation factor $\delta$ from equation $\mathrm{A} 4$. The results of the calculations are shown in Table 3 for altitudes of $300 \mathrm{~km}$. and $500 \mathrm{~km}$. and two values of $\lambda_{\mathrm{x}}$ equal to $260 \mathrm{~km}$. and $520 \mathrm{~km}$. with

$$
\begin{aligned}
\omega & =10^{-3} \mathrm{sec}^{-1} \\
\mathrm{H} & =40 \mathrm{~km} \\
\omega_{\mathrm{g}} & =7 \times 10^{-3} \mathrm{sec}^{-1} \\
\mathrm{C}_{\mathrm{s}} & =0.7 \mathrm{~km} / \mathrm{sec} \\
\gamma & =1.5 \\
\omega_{\mathrm{h}} & =\left\{\begin{array}{l}
7 \times 10^{-2} \mathrm{sec}^{-1} \text { at } 300 \mathrm{~km} \text { altitude } \\
7 \times 10^{-4} \mathrm{sec}^{-1} \text { at } 500 \mathrm{~km} \text { altitude. }
\end{array}\right.
\end{aligned}
$$

The values of $\delta$ indicate that the attenuation of the wave amplitude is smaller for the larger horizontal wave length as suggested by Equation A4. For this wave length the amplitude falls to $e^{-1}$ after the wave has traveled vertically upward approximately $300 \mathrm{~km}$. It is also evident from the data in Table 3 that the wavefront and direction of energy propagation change with altitude and become nearly vertical above $500 \mathrm{~km}$. altitude. 


\section{DISCUSSION AND CONCLUSION}

The consistency in the apparent wavelengths observed at various altitudes indicates that the same phenomenon is being repeatedly observed on different days. With this assumption it is possible to explain the observations on the basis of waves propagating in the neutral thermosphere with horizontal wavelengths such that the apparent altitudinal variation of half-wavelength is due primarily to the variation of the vertical satellite velocity. It then appears that the waves are gravity waves propagating predominently horizontally in a north-south or south-to-north direction:

This conclusion is consistent with the results reported by Thome (1964) and Georges (1967) if it is assumed that the wave phenomena reported here is the underlying cause of the ionospheric effects with similar characteristics. This result supercedes the earlier preliminary conclusion (Newton, et al., 1967) in which purely horizontally propagating waves were excluded because of; 1) underestimation of the doppler effects due to satellite motion; 2) the obscuration of extrema in the density data at perigee by local time changes and 3) an overestimation of the accuracy of the extrema locations in time and space.

The small effective frequency spread observed may result from possible filtering action of the atmosphere in addition to any frequency characteristics of the unknown wave source. It is interesting to note with respect to a wave source however, that in addition to an apparent relationship between the frequency of observations of the wave structure and proximity to the auroral zone, there might also be a relationship with the polar frontal zone cyclogenesis. 
The energy propagated by the observed waves appears to be very small relative to the EUV energy flux into the thermosphere from the sun. The small energy flux could perhaps account for the waves being observed almost exclusively in the late evening and early morning hours. If the energy flux of the wave is considered to be constant, then the density perturbation of the wave might be larger in a less dense atmosphere. Hence, the diurnal density variation could reduce the density perturbation to a value below the experiment detection threshold during the day. Further, it is possible that energy transmission characteristics of the atmosphere could perhaps change diurnally thus diurnally changing the ability of the waves to propagate upward from lower altitudes. 


\section{APPENDIX}

The dispersion formula of neutral air waves within an isothermal thermosphere with finite heat conduction according to Pitteway and Hines (1963) is (using the notation of Volland (1968))

$\mathrm{q}= \pm \sqrt{\frac{\gamma}{2}-\mathrm{s}^{2}-\frac{\omega_{\mathrm{a}}^{2}}{\omega^{2}}-\mathrm{j} \frac{\omega_{\mathrm{h}}}{\omega} \mp \sqrt{\left(\frac{\gamma}{2}-\mathrm{j} \frac{\omega_{\mathrm{h}}}{\omega}\right)^{2}+\frac{2 \mathrm{j} \omega_{\mathrm{h}}}{\omega}\left(1+\frac{\omega_{\mathrm{g}}^{2}}{\omega^{2}} \mathrm{~s}^{2}\right)}}$

with

$$
\begin{gathered}
\mathrm{q}=\frac{\mathrm{k}_{\mathrm{z}}}{\mathrm{k}} ; \quad \mathrm{k}=\frac{\omega}{\mathrm{C}_{\mathrm{s}}} ; \quad \omega_{\mathrm{g}}=\sqrt{\gamma-1} \frac{\mathrm{g}}{\mathrm{C}_{\mathrm{s}}} \\
\mathrm{S}=\frac{\mathrm{k}_{\mathrm{x}}}{\mathrm{k}} ; \quad \omega_{\mathrm{a}}=\frac{\gamma \mathrm{g}}{2 \mathrm{C}_{\mathrm{s}}} ; \quad \omega_{\mathrm{h}}=\frac{\gamma \mathrm{g}}{2 \mathrm{C}_{\mathrm{h}}} \\
\mathrm{C}_{\mathrm{s}}=\sqrt{\gamma \frac{\mathrm{R}}{\mathrm{M}} \mathrm{T}} \quad \text { (velocity of sound) } \\
\mathrm{C}_{\mathrm{h}}=\frac{k}{\mathrm{C}_{\mathrm{p}} \rho \mathrm{H}} \\
\text { (heat conduction velocity) } \\
\begin{array}{l}
\text { (ratio between the specific heat at constant pressure } \\
\mathrm{c}_{\mathrm{p}}
\end{array} \\
\text { and constant volume) }
\end{gathered}
$$

$R$ ideal gas constant

M molecular weight

T temperature 
g gravitational acceleration

$\rho$ density of the neutral air

$\mathrm{H}$ scale height

$\kappa$ coefficient of heat conductivity.

The plus sign outside the square root in Equation 6 is for downgoing waves, the minus sign is for upgoing waves. The plus sign inside the square root gives heat conduction waves, the minus sign gives acoustic-gravity waves.

Equation A1 can be written

$$
\pm \mathbf{q}=\alpha-\mathbf{j} \beta,(\beta \geqq 0)
$$

where $\alpha$ is the real part of $\mathrm{q}$ and $\beta$ is the imaginary part. The real part is related to the phase velocity of the wave, $V$, by

$$
V=\frac{\mathrm{C}_{\mathrm{s}}}{\sqrt{\alpha^{2}+\mathrm{S}^{2}}}
$$

The imaginary part is related to the attenuation factor, $e^{\delta\left(z-z_{0}\right)}$, of the wave during its vertical propagation by

$$
\delta=\overline{+} \mathbf{k} \beta+\frac{1}{2 \mathrm{H}}
$$

For upward propagating waves the minus sign is used and for downward propagating waves the plus sign is used. Thus; it is seen that $\delta$ is always positive for downward propagating waves and that these waves are always strongly damped 
in distances comparable to or less than two scale heights. For upward propagating waves, $\delta$ is the difference between two positive values and the waves will be amplified or attenuated depending on the specific value of this difference.

For gravity waves, using ray optics, the angle between the vertical direction and the direction of phase propagation, $\vartheta_{\mathrm{ph}}$, is given by

$$
\tan \vartheta_{\text {ph }}=\frac{\mathrm{S}}{\alpha}
$$

The angle between the vertical direction and the direction of energy propagation, $\vartheta_{\text {en }}$, is given by

$$
\tan \vartheta_{\text {en }}=-\frac{\partial \alpha}{\partial S}
$$

For altitudes greater than or near $500 \mathrm{~km}$ and $\omega \leq 10^{-3} \mathrm{rad} / \mathrm{sec}$, and $\mathrm{S}>10$ we have

$$
\mathrm{S}^{2}+\left(\frac{\omega_{\mathrm{a}}}{\omega}\right)^{2} \gg \sqrt{\frac{\omega_{\mathrm{h}}}{\omega}} \frac{\omega_{\mathrm{g}}}{\omega} \mathrm{S} \gg \sqrt{\left(\frac{\gamma}{2}\right)^{2}+\left(\frac{\omega_{\mathrm{h}}}{\omega}\right)^{2}}
$$

and therefore for upgoing gravity waves

$$
\begin{aligned}
& \alpha \approx-\frac{\omega_{\mathrm{g}} \mathrm{S}}{2 \omega \beta} \sqrt{\frac{\omega_{\mathrm{h}}}{\omega}} . \\
& \beta \approx \sqrt{\left(\frac{\omega_{\mathrm{a}}}{\omega}\right)^{2}+\mathrm{S}^{2}}
\end{aligned}
$$


Thus,

$$
\tan \vartheta_{\mathrm{ph}} \approx \frac{-2 \omega \beta}{\omega_{\mathrm{g}} \sqrt{\frac{\omega_{\mathrm{h}}}{\omega}}}
$$

indicating the well known downward phase propagation of upward propagating gravity waves. It is also seen from Equation A8 that the direction of phase propagation approaches the horizontal with increasing altitude because $\omega_{h}$ decreases with height. The attenuation factor becomes larger as the horizontal wavelength decreases indicating that the smaller horizontal wavelengths are attenuated more than the larger horizontal wavelengths at these altitudes.

\section{ACKNOWLEDGMENTS}

We would like to acknowledge the valuable help received from: Mr. Henry Benton and Mr. Donald Williams in the preparation and checkout of the experiment electronics; Mr. Hanson Powers and Mr. Leland Clark in the packaging of the flight sensors; Mrs. Virginia Zanner in the computer programs for data analysis, and Mr. Donald Greer, Mrs. Diana Thompson and Mr. Robert Beaty in the data reduction and display. The help of all the numerous project personnel is gratefully acknowledged.

One of us (H. Volland) is grateful to the National Academy of Sciences National Research Council for a Senior Research Associateship. 


\section{REFERENCES}

Georges, T. M., HF-Doppler Studies of Traveling Ionospheric Disturbances, AGARD XIII Symposium on Phase and Frequency Instability in Electromagnetic Wave Propagation, Ankara, Turkey, Oct., 1967.

Havens, R. J., R. T. Koll and H. E. LaGow, The Pressure, Density, and Temperature of the Earth's Atmosphere to 160 Kilometers, J. Geophys. Res., $\underline{57} \mathrm{pp} .59-72,1952$.

Heisler, L. H., Traveling Ionospheric Disturbances, Space Research VII, edited by R. L. Smith-Rose, pp. 55-65, North-Holland Publishing Company, Amsterdam, 1967.

Hines, C. O., Internal Atmospheric Gravity Waves at Ionospheric Heights. Can. J. Phys. $\underline{38}, 1441-1481,1960$.

Hines, C. O., Some Consequences of Dissipative Effects in the Propagation of Atmospheric Gravity Waves in the F Region, IAGA/URSI Symposium on Upper Atmospheric Winds, Waves, and Ionospheric Drifts, St. Gallen, Switzerland, Oct. 1967.

Horowitz, R. and D. Kleitman, Upper Atmosphere Research Report 18, NRL Report 4246, U.S. Naval Research Laboratory, Wash. D. C. Oct., 1953. Newton, G. P., R. Horowitz and W. Priester, Atmospheric Density and Temperature Variations from the Explorer 17 Satellite and a Further Comparison with Satellite Drag. Planet. Space Sci. 13, 599-616, 1965.

Newton, G. P., D. T. Pelz, G. E. Miller, and R. Horowitz, Response of Modified Redhead Magnetron and Bayard-Alpert Vacuum Gauges Aboard Explorer 17, Transactions of the Tenth National Vacuum Symposium, Edited by George H. Bancroft, pp. 208-212, The Macmillan Company, New York, 1963. 
Newton, G. P., D. T. Pelz and H. Volland, Characteristics of Wave Structure in the Neutral Thermosphere, submitted for publication in Space Research VII, and presented at the 10th Plenary Meeting of COSPAR, London, England, 28 July 1967.

Pelz, D. and G. Newton, Pressure Conversion Constants for Magnetron Ionization Gauges, J. Vac. Sci. and Tech. $\underline{4}$ Sept.-Oct., 1967.

Pitteway, M. L. V., C. O. Hines, The Viscous Damping of Atmospheric Gravity Waves, Can. J. Phys. $\underline{41}$, 1935-1948, 1963.

Redhead, P. A., The Magnetron Gauge; A Cold Cathode Vacuum Gauge. Can. J. Phys. 37, 1260-1271, 1959.

Schultz, F. V., N. W. Spencer, and A. Reifman, Upper Air Research Program, Progress Report 2, Contract W-33-038, AC-14050, Engineering Res. Inst., Univ. Mich., p. 129, July, 1948.

Thome, G. D., Incoherent Scatter Observations of Traveling Ionospheric Disturbances, J. Geophys. Res. 69 , pp. 4047-4049, 1964.

Volland, H., The Upper Atmosphere as a Multiple Refractive Medium for Neutral Air Motions, submitted for publication to Journ. Atm. Terr. Phys., 1968. 
Table I gives a summary of the altitude and time (from an arbitrary zero) of the extrema for turn-ons analyzed which show density structure. Also given are estimates of the horizontal and vertical satellite velocity components at the start and end altitudes corresponding to the density structure.

Table II gives a summary of the apparent vertical half-wavelengths and their mean altitude along with other pertinent information about the turn-on and density structure.

Table III gives a summary of calculated propagation parameters for gravity waves with horozontal wavelengths of $260 \mathrm{~km}$ and $520 \mathrm{~km}$ at $300 \mathrm{~km}$ and $500 \mathrm{~km}$ altitudes. 
Table I

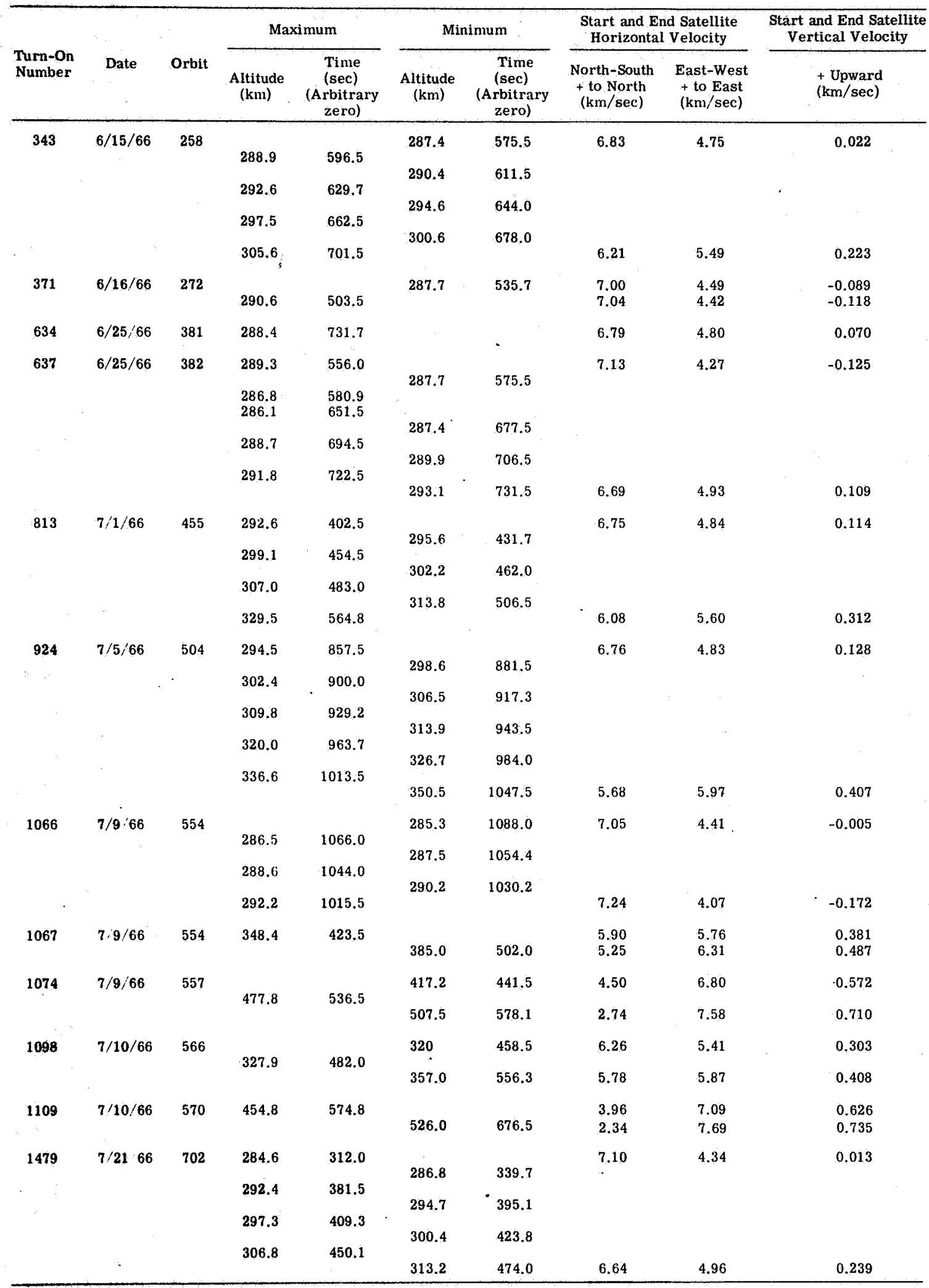


Table II

\begin{tabular}{|c|c|c|c|c|c|c|c|c|c|c|c|c|c|c|}
\hline $\begin{array}{l}\text { Turn-On } \\
\text { Number }\end{array}$ & Date & $\begin{array}{c}\text { Averi } \\
\text { GM } \\
(\mathrm{hr} . \mathrm{n}\end{array}$ & $\begin{array}{l}\text { rage } \\
\text { MT } \\
\text { min) }\end{array}$ & $\begin{array}{l}\text { Axe rape } \\
\text { Lutal Tinu } \\
\text { (heurs) }\end{array}$ & 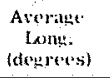 & $\begin{array}{l}\text { Averitge } \\
\text { Lat. } \\
\text { fdegreess }\end{array}$ & $\begin{array}{l}\text { Meatu } \\
\text { Alt itudc } \\
(\mathrm{km})\end{array}$ & $\begin{array}{c}\text { Shortest } \\
2 \\
(\mathrm{~km})\end{array}$ & $\begin{array}{c}\text { Longest } \\
2 \\
(\mathrm{~km})\end{array}$ & $\left(\min \left(\mathrm{m}^{3}\right)\right.$ & $\underset{(\mathrm{H}}{\overline{\mathrm{H}}}$ & $\begin{array}{l}\text { Vortical Direction } \\
\text { of Satellite Motion }\end{array}$ & $\begin{array}{l}\text { Geomagnetic } \\
\text { Activity }\end{array}$ & $\begin{array}{l}\text { Wave } \\
\text { Half-Amplitude }\end{array}$ \\
\hline 343 & 61566 & 090 & 04 & 5.82 & -48.7 & 47.2 & $\begin{array}{l}288 \\
290 \\
292 \\
294 \\
296 \\
299 \\
304\end{array}$ & $\begin{array}{l}1.6 \\
1.5 \\
2.2 \\
2.1 \\
2.9 \\
3.6 \\
4.5\end{array}$ & 8.9 & $\begin{array}{l}1.4^{14} \\
1.3^{14} \\
1.25^{14} \\
1.2^{14} \\
1.1^{24} \\
1.05^{-14} \\
9.5^{14}\end{array}$ & $\begin{array}{l}36.2 \\
36.3 \\
36.4 \\
36.6 \\
36.7 \\
36.9 \\
37.2\end{array}$ & 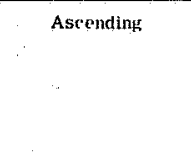 & . & $10-15 \%$ \\
\hline 371 & 61606 & 120 & 04 & 4.64 & -111.5 & 31.8 & $\begin{array}{l}290 \\
292\end{array}$ & 3.4 & 5.8 & $\begin{array}{l}1.4^{14} \\
1.3^{14}\end{array}$ & $\begin{array}{l}36.3 \\
36.4\end{array}$ & Descending & - & $10 \%$ \\
\hline 634 & 62566 & 065 & 53 & 3.60 & -49.3 & 45.4 & 288 & & 3.3 & $2.2^{14}$ & 36.2 & Ascconding & D & $10^{6}$ \\
\hline 637 & 62566 & 084 & 47 & 3.30 & -2.0 & 40.9 & $\begin{array}{l}288 \\
287 \\
287 \\
2 H 4 \\
289 \\
291 \\
292\end{array}$ & $\begin{array}{l}1.4 \\
1.2 \\
1.4 \\
1.4 \\
1.3 \\
1.9 \\
1.4\end{array}$ & & $\begin{array}{ll}2.1 & 1.4 \\
2.2 & 14 \\
2.1 & 14 \\
2.0 & 14 \\
1.9 & 14 \\
1.7 & 14 \\
1.6^{-14}\end{array}$ & $\begin{array}{l}36.8 \\
36.1 \\
36.1 \\
36.2 \\
36.2 \\
36.4 \\
36.4\end{array}$ & Perigee Pass & $\mathrm{D}$ & $10^{\prime}$ \\
\hline 813 & 7166 & $05:$ & 59 & 2.60 & -50.7 & 48.0 & $\begin{array}{l}294 \\
297 \\
301 \\
305 \\
310 \\
316 \\
321\end{array}$ & $\begin{array}{r}3.0 \\
3.5 \\
3.1 \\
4.6 \\
6.8 \\
13.7\end{array}$ & 16.7 & 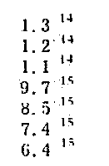 & $\begin{array}{l}36.6 \\
36.8 \\
37.0 \\
37.3 \\
37.6 \\
38.0 \\
38.3\end{array}$ & Aste'endini & - & $10-20 \%$ \\
\hline .924 & 7566 & 04 & 42 & 1.76 & -44.1 & 48.0 & $\begin{array}{l}297 \\
300 \\
304 \\
308 \\
312 \\
310 \\
323 \\
332 \\
344\end{array}$ & $\begin{array}{r}4.1 \\
3.8 \\
4.1 \\
3.3 \\
4.1 \\
6.1 \\
6.7 \\
9.9 \\
13.9\end{array}$ & & $\begin{array}{l}1.15^{14} \\
1.05^{14} \\
9.6^{12} \\
8.7^{15} \\
7.9^{15} \\
7.1^{15} \\
6.0^{15} \\
4.8^{15} \\
3.5^{15}\end{array}$ & $\begin{array}{l}36.8 \\
37.0 \\
37.2 \\
37.5 \\
37.7 \\
38.0 \\
38.5 \\
39.1 \\
39.9\end{array}$ & Ascending & - & $10-15^{\circ}$ \\
\hline 1066 & 7966 & 05 & 16 & 23.7 & -83.5 & 27.2 & $\begin{array}{l}286 \\
287 \\
288 \\
289 \\
291\end{array}$ & $\begin{array}{l}1.1 \\
1.0 \\
1.2 \\
1.7 \\
2.0\end{array}$ & & $\begin{array}{l}2.3^{34} \\
2.2^{14} \\
2.155^{14} \\
2.10^{14} \\
2.0^{14}\end{array}$ & $\begin{array}{l}36.1 \\
36.1 \\
36.2 \\
36.3 \\
36.4\end{array}$ & Descending & D & $10 \%$ \\
\hline 1067 & 7966 & 05 & 24 & 1.6 & -56.7 & 54.4 & $\begin{array}{l}350 \\
361 \\
382\end{array}$ & & $\begin{array}{l}27.5 \\
24.0 \\
37.0\end{array}$ & $\begin{array}{l}7.0^{15} \\
5.8^{15} \\
3.7^{15}\end{array}$ & $\begin{array}{l}40.3 \\
41.0 \\
42.4\end{array}$ & Ascending & $\mathrm{D}$ & $20-25 \%$ \\
\hline 1074 & 7966 & 11 & 15 & 2.9 & -125.3 & 61.1 & $\begin{array}{l}472 \\
.511\end{array}$ & $\begin{array}{l}52 \\
37\end{array}$ & & $\begin{array}{l}5.0^{-16} \\
2.1^{-16}\end{array}$ & $\begin{array}{l}48.2 \\
50.7\end{array}$ & Ascending & $\mathrm{D}$ & $20-30 \%$ \\
\hline 1098 & 71066 & 04 & 36 & 1.1 & -52.4 & 51.7 & $\begin{array}{l}324 \\
332 \\
356\end{array}$ & 8.2 & $\begin{array}{l}18.0 \\
30.0\end{array}$ & $\begin{array}{l}5.9^{15} \\
5.0^{-15} \\
3.1^{\cdot 15}\end{array}$ & $\begin{array}{l}38.6 \\
39.1 \\
40.7\end{array}$ & Ascending & $\mathrm{D}$ & $10-15 \%$ \\
\hline 1109 & $710: 66$ & 12 & 24 & 3.2 & -137.6 & 62.6 & 528 & 85 & & $1.7^{-16}$ & 51.7 & Ascendìng & $\mathrm{D}$ & $25-35 \%$ \\
\hline 1479 & 72166 & 03 & 27 & 21.9 & -83.2 & 40.4 & $\begin{array}{l}286 \\
294 \\
296 \\
299 \\
310\end{array}$ & $\begin{array}{l}2.1 \\
2.3 \\
2.6 \\
3.1 \\
6.5\end{array}$ & & $\begin{array}{l}2.0^{-14} \\
1.5^{-14} \\
1.4^{-14} \\
1.3^{-14} \\
1.05^{-14}\end{array}$ & $\begin{array}{l}36.1 \\
36.6 \\
36.7 \\
36.9 \\
37.6\end{array}$ & Ascending & $\mathrm{D}$ & $10 \%$ \\
\hline
\end{tabular}


Table III

\begin{tabular}{|c|c|c|c|c|c|c|c|c|}
\multicolumn{1}{c|}{} & \multicolumn{3}{|c|}{$\lambda_{\mathrm{x}}=260 \mathrm{~km}$} & \multicolumn{4}{c|}{$\lambda_{\mathrm{x}}=520 \mathrm{~km}$} \\
\cline { 2 - 8 } Alt $(\mathrm{km})$ & $\vartheta_{\mathrm{ph}}$ & $\vartheta_{\text {en }}$ & $\delta\left(\mathrm{km}^{-1}\right)$ & $\lambda_{\mathrm{z}} / 2(\mathrm{~km})$ & $\vartheta_{\mathrm{ph}}$ & $\vartheta_{\text {en }}$ & $\delta\left(\mathrm{km}^{-1}\right)$ & $\lambda_{\mathrm{z}} / 2(\mathrm{~km})$ \\
\cline { 2 - 8 } 500 & $150^{\circ}$ & $36^{\circ}$ & $-1.2^{-2}$ & 75 & $160^{\circ}$ & $53^{\circ}$ & $-3.6^{-3}$ & 110 \\
& $100^{\circ}$ & $0.7^{\circ}$ & $-1.2^{-2}$ & 350 & $110^{\circ}$ & $8^{\circ}$ & $-2.5^{-3}$ & 400 \\
\hline
\end{tabular}




\section{FIGURE CAPTIONS}

Figure 1. Artist conception of Explorer 32 in orbit.

Figure 2. Cross sections of the Explorer 32 magnetron gauges. The GCA-R5 gauge is on top and has a stainless steel envelope. The NRC-528 gauge is on the bottom and has a glass envelope. Both orifice pieces are made of Kovar. No magnets are shown.

Figure 3. Atmospheric density measured on turn-on 2762 over Rosman, North Carolina; on 25 August, 1966. The mean GMT of this pass was 19 hours 34 minutes and the mean local solar time (LST) is 14.3 hours. The line represents a least squares fit to the data of an exponential dependence of density on altitude. The individual points are the density measurement made during each satellite spin by one gauge system.

Figure 4. Maximum and minimum gauge pressures during each satellite spin measured on turn-on 924. The local variations in the maximum pressure indicate structure in the atmospheric density.

Figure 5. Atmospheric density measured on turn-on 924 over Saint Johns, Newfoundland, on $5 \mathrm{July}, 1966$. The mean GMT is 4 hours 42 minutes and the mean LST is 1.8 hours. The line and points have the same description as in Figure 3.

Figure 6. Atmospheric density measured on turn-on 1067 over Saint Johns, Newfoundland, at a mean GMT of 5 hours 24 minutes on 9 July, 1966. The mean LST was 1.6 hours. 
Figure 7. Atmospheric density measured at perigee during turn-on 637 over Rosman, North Carolina, at 8 hours 48 minutes GMT on 25 June, 1966. The mean LST was 3.2 hours. The numbers denote local maxima and minima in the density structure.

Figure 8. Semi-logarithmic plot of apparent vertical half-wavelengths of waves propagating in the neutral atmosphere versus mean altitude of the halfwavelength. The solid lines marked $1,2,3,4$ are calculated from Equation 4 neglecting the phase integral of Real $\left(k_{z}\right)$ and using the values $\omega_{\text {eff }}=0.1,0.2,0.3$, and 0.4 respectively. The dashed lines marked $1^{\prime}$ and $1^{\prime \prime}$ were calculated from Equation 4 including the phase integral using $\omega_{\text {ef }}=0.1$ and a horizontal : wavelength of $628 \mathrm{~km}$ and period of $6283 \mathrm{sec}$ for the satellite ascending and descending respectively.

Figure 9. Projections of satellite locations onto a world map for turn-ons for which atmospheric densities were measured on days when waves were observed. Turn-ons when waves were observed are dashed. The numbers beside the passes are orbit numbers.

Figure 10. Locations on the satellite orbit of the maxima and minima of the density structure on turn-on 637 . The numbers denote the same points as in Figure 7. The dark regions represent estimates of the possible spread in the observed location of the extrema of the density. The equally spaced lines of constant phase are drawn for a time separation of 16 sec. corresponding to $\omega_{\text {eff }}=0.2$. 


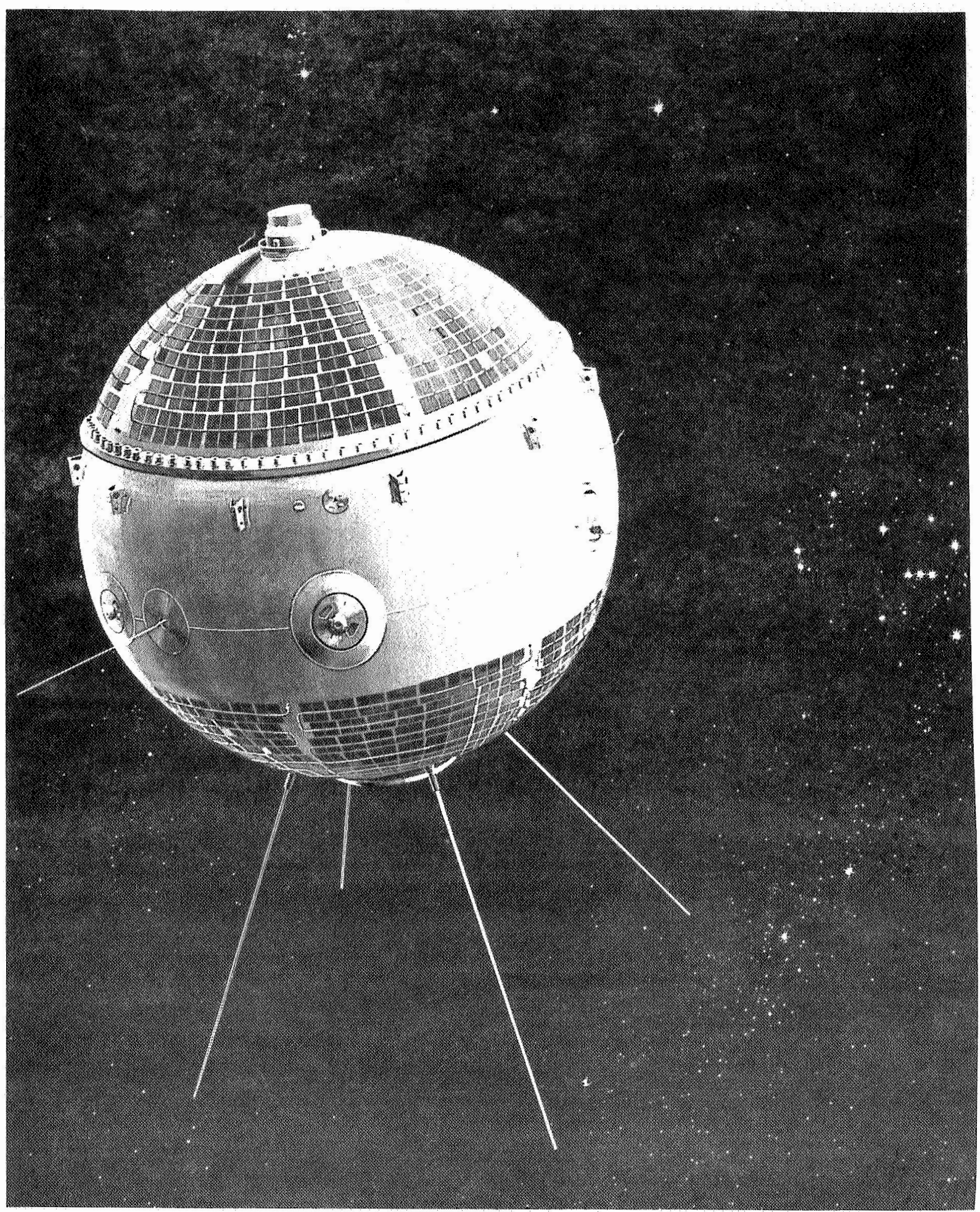

Figure 1. Artist Conception of Explorer 32 in Orbit. 


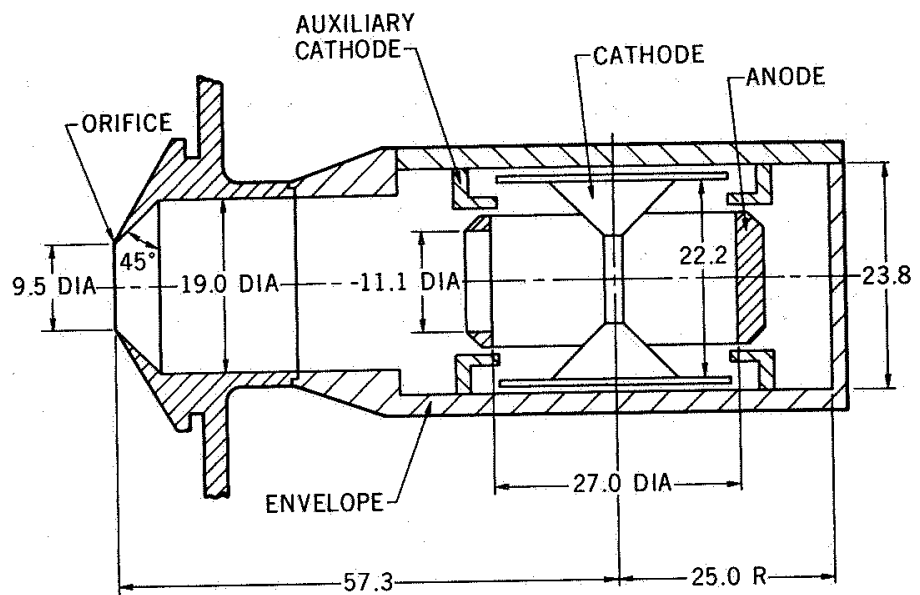

ALL DIMENSIONS IN MILLIMETERS

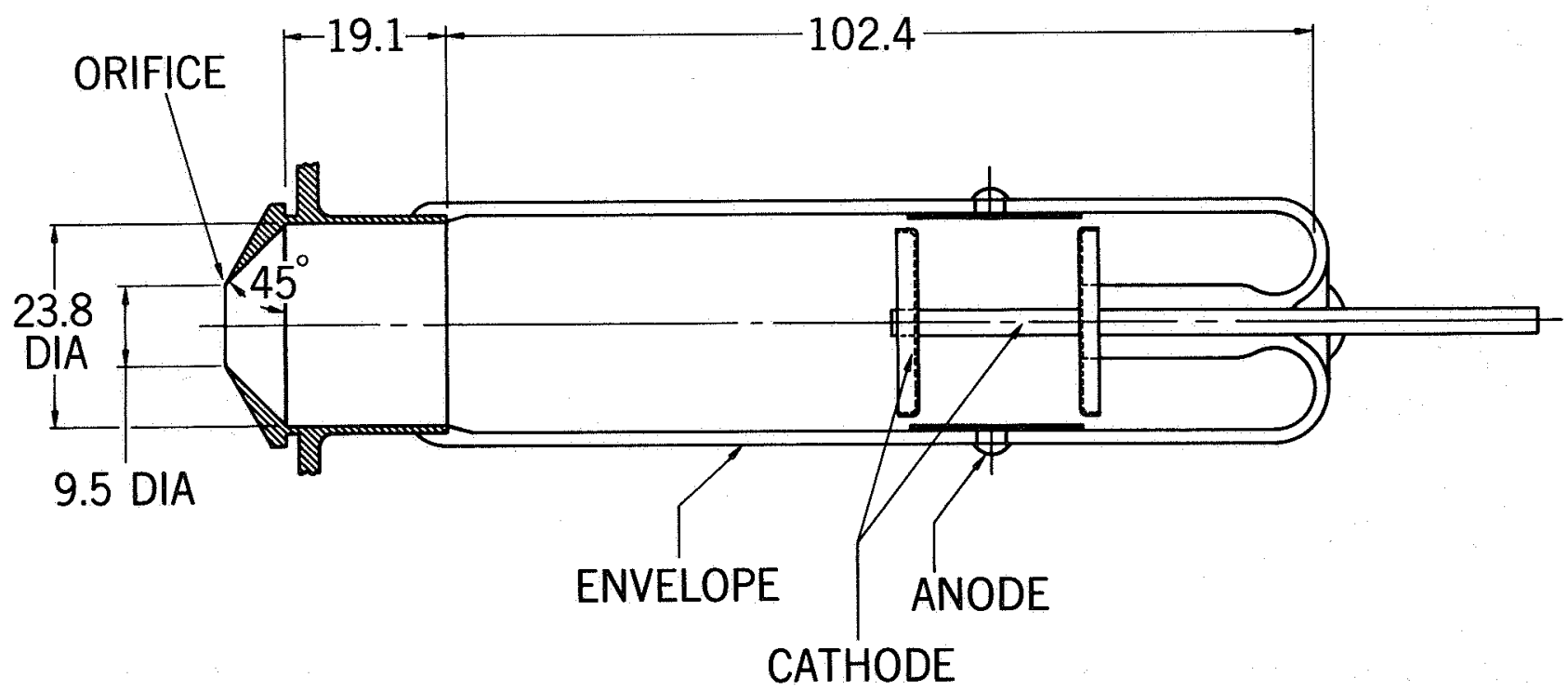

Figure 2. Cross Sections of the Explorer 32 Magnetron Gauges. The GCA-R5 Gauge is on Top and Has a Stainless Steel Envelope. The NRC-528 Gauge is on the Bottom and Has a Glass Envelope. Both Orifice Pieces are Made of Kovar. No Magnets are Shown. 


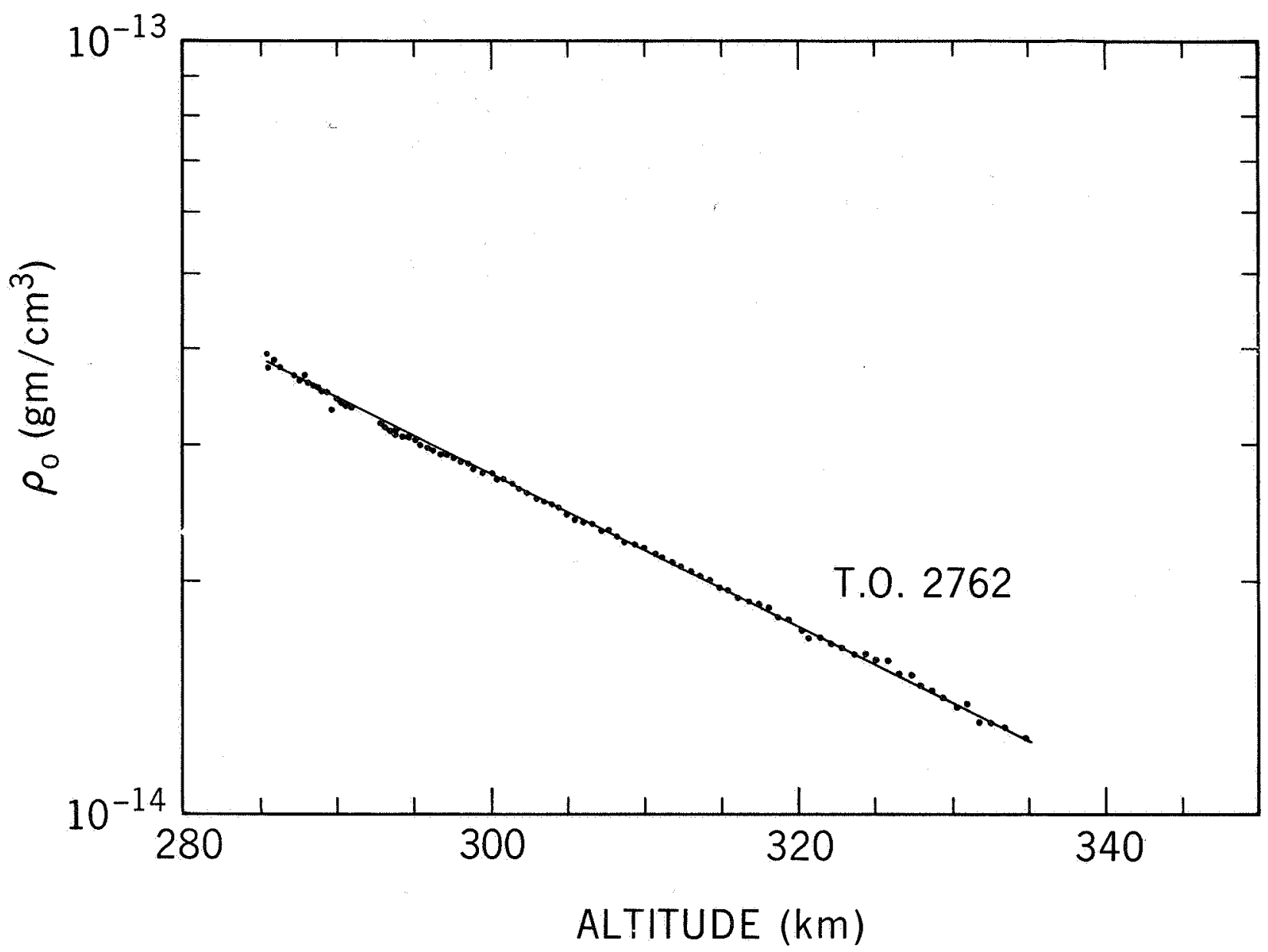

Figure 3. Atmospheric Density Measured on Turn-On 2762 Over Rosman, North Carolina; on 25 August, 1966. The Mean GMT of this Pass was 19 Hours 34 Minutes and the Mean Local Solar Time (LST) is 14.3 Hours. The Line Represents a Least Squares Fit to. the Data of an Exponential Dependence of Density on Altitude. The Individual Points are the Density Measurement Made During Each Satellite Spin by One Gauge System. 


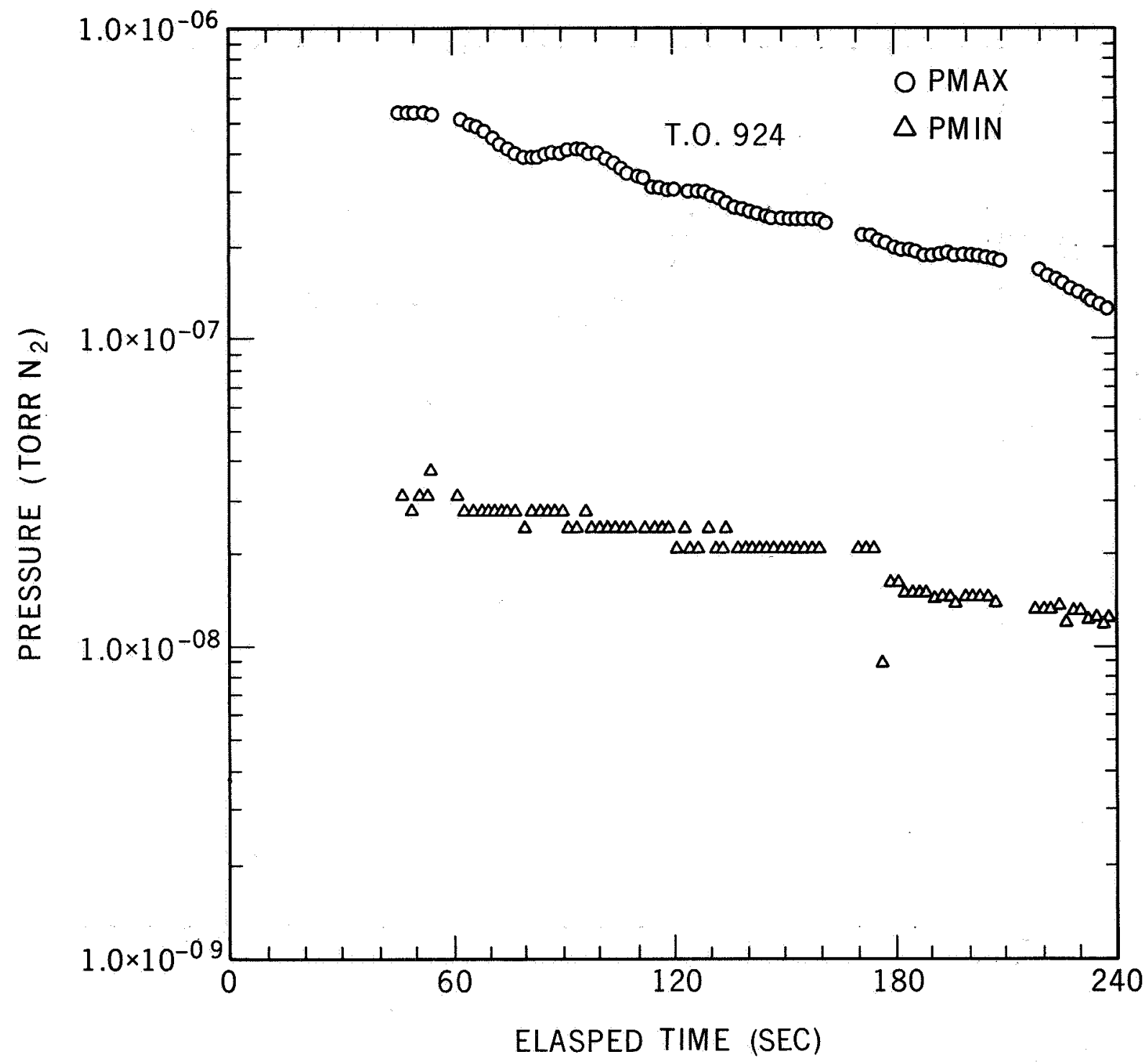

Figure 4. Maximum and Minimum Gauge Pressures During Each Satellite Spin Measured on Turn-On 924. The Local Variations in the Maximum Pressure Indicate Structure in the Atmospheric Density. 


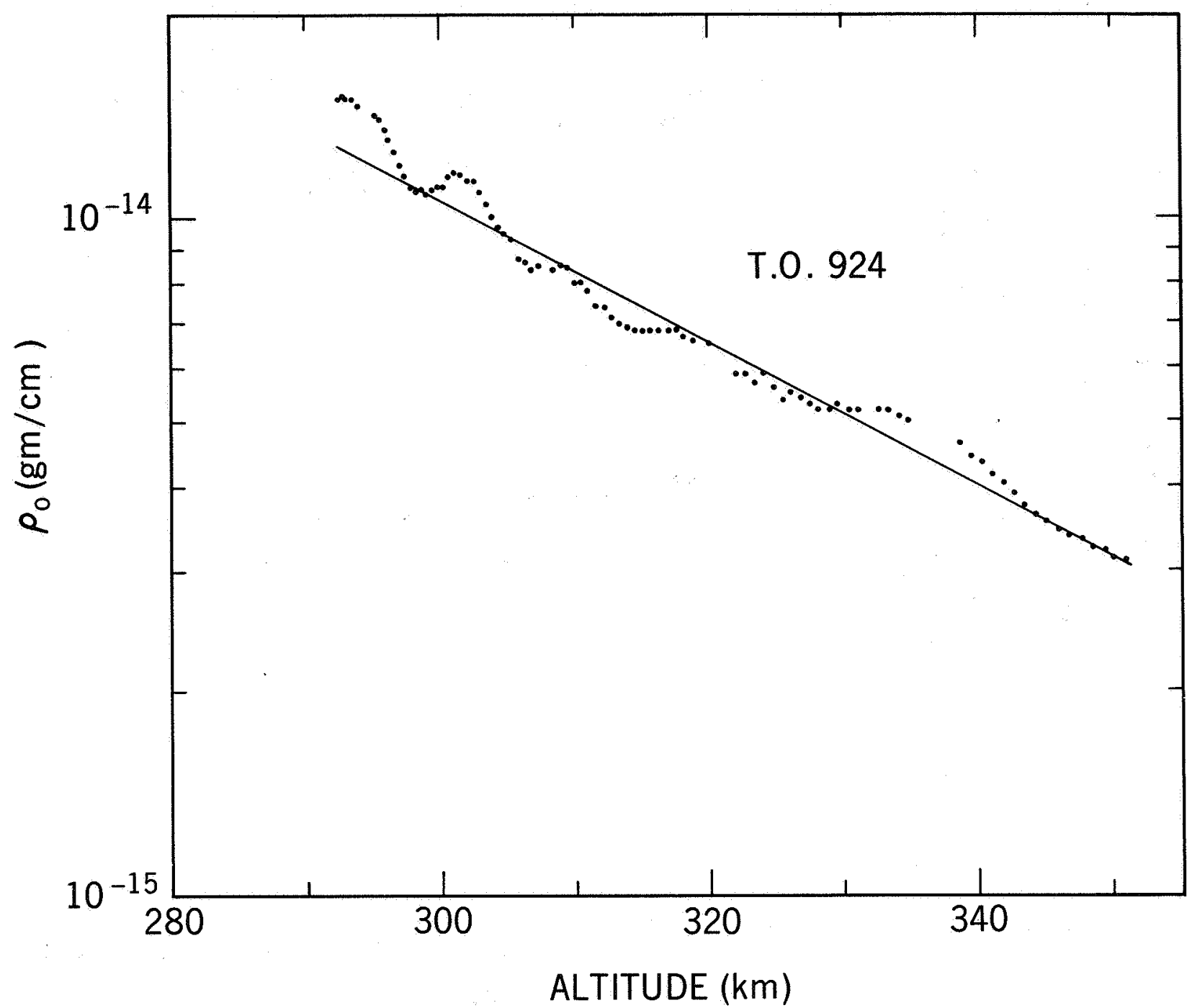

Figure 5. Atmospheric Density Measured on Turn-On 924 Over Saint Johns, Newfoundland, on 5 July, 1966. The Mean GMT is 4 Hours 42 Minutes and the Mean LST is 1.8 Hours. The Line and Points Have the Same Description as in Figure 3. 

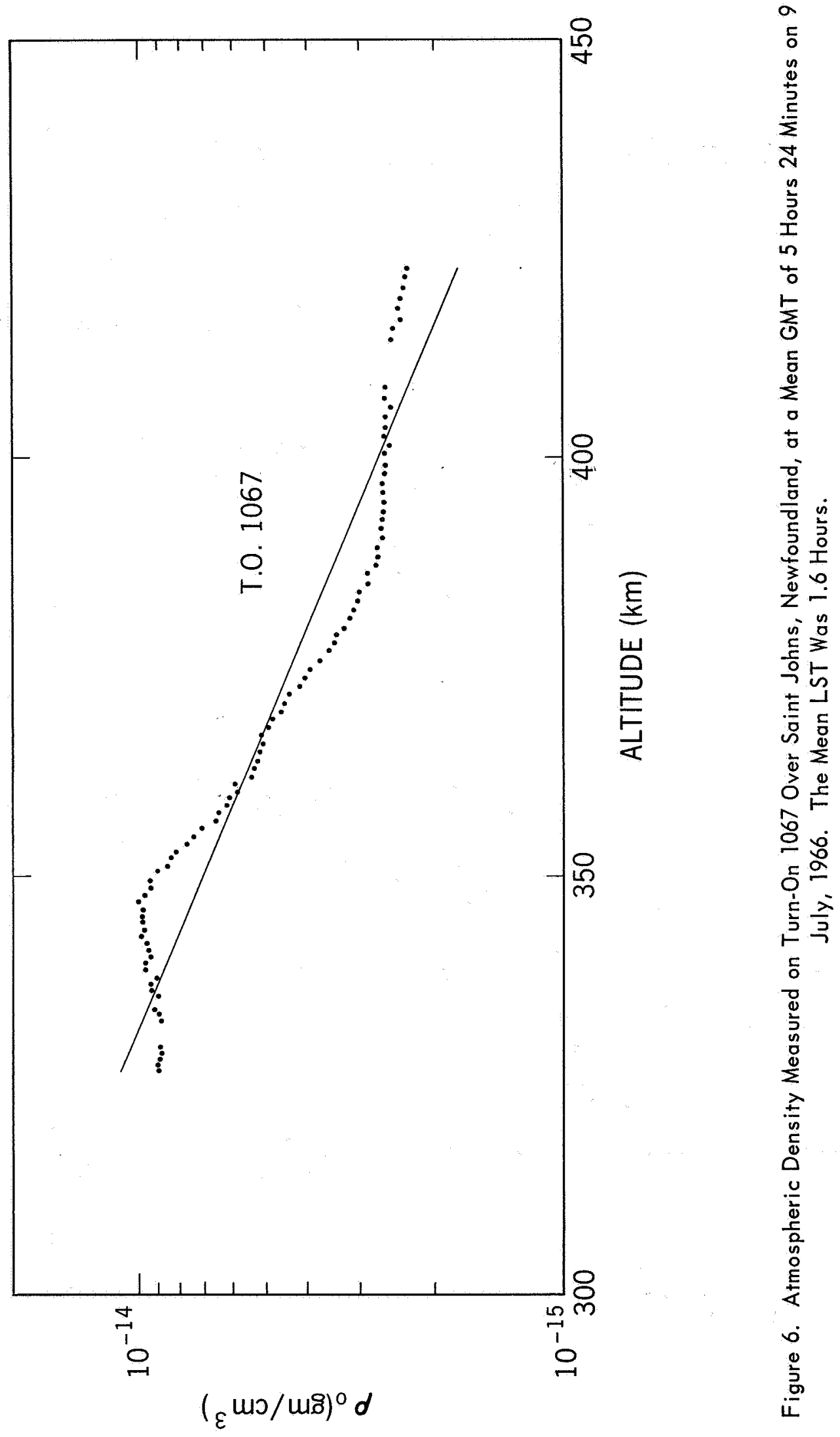


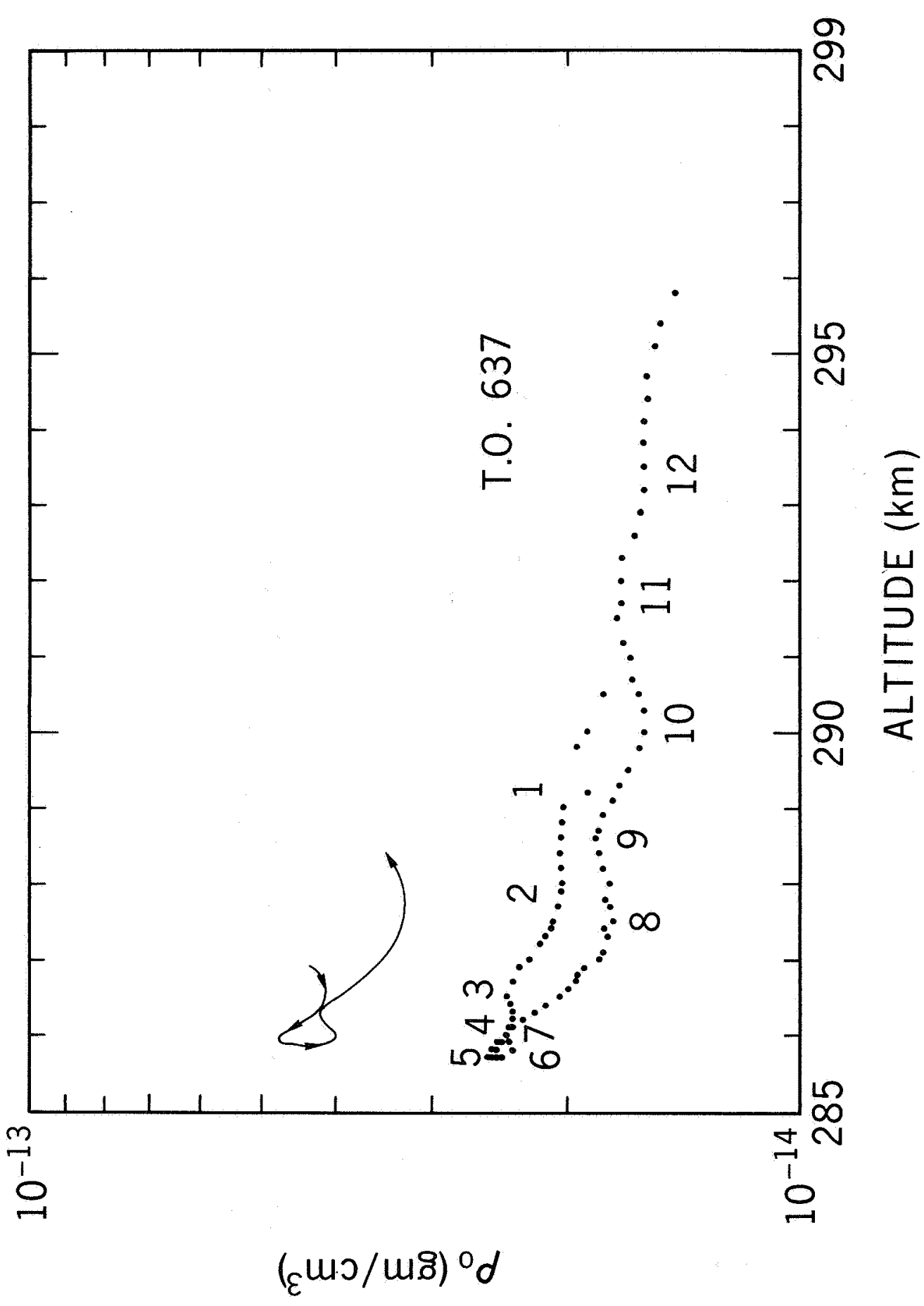

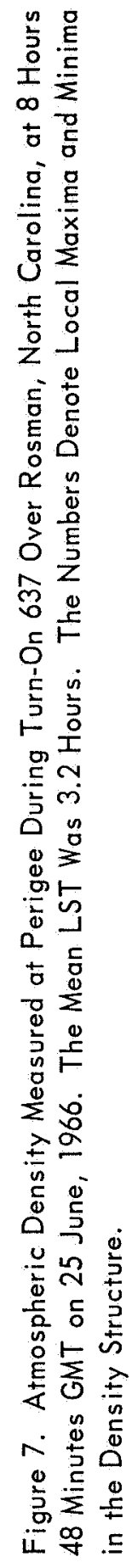




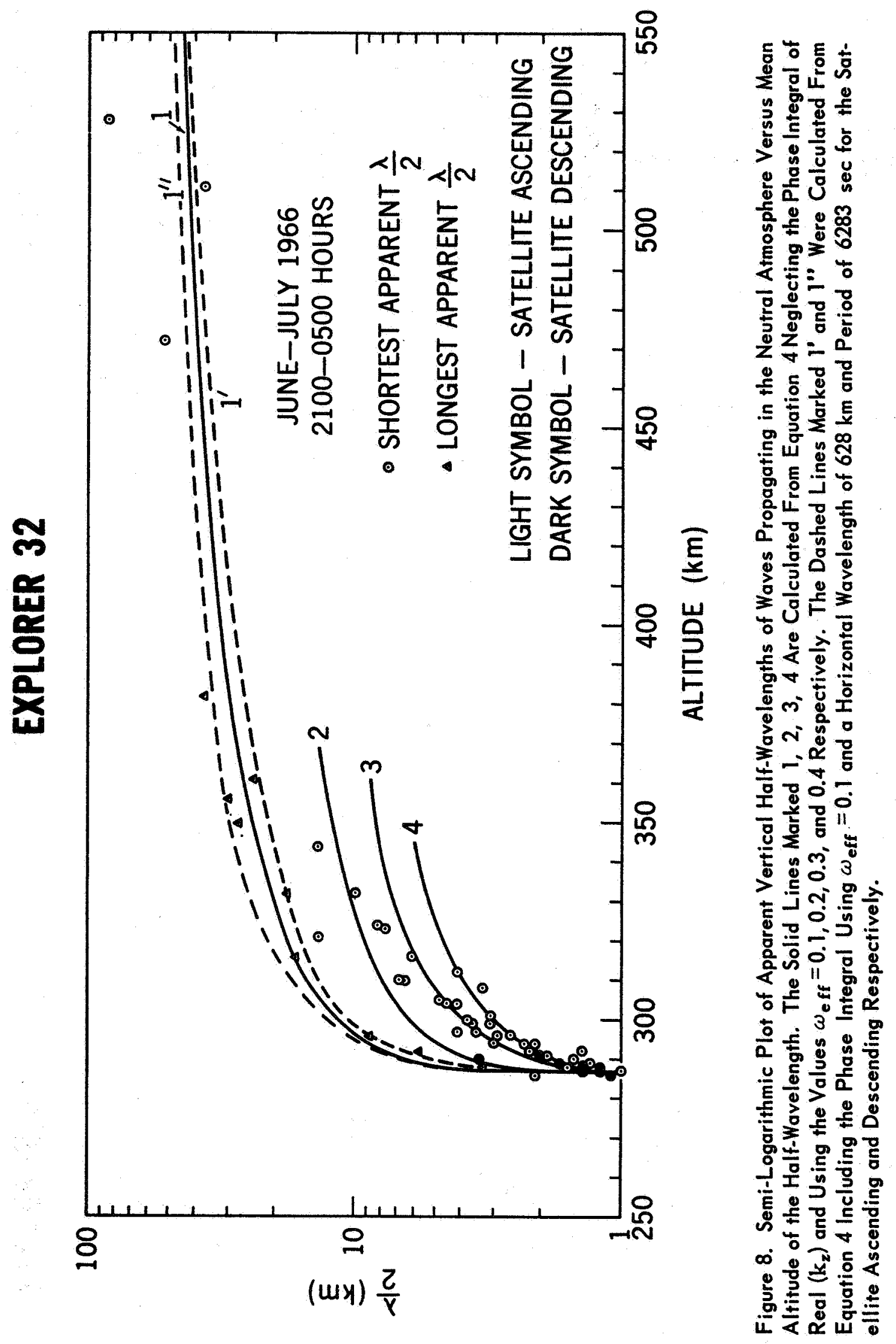




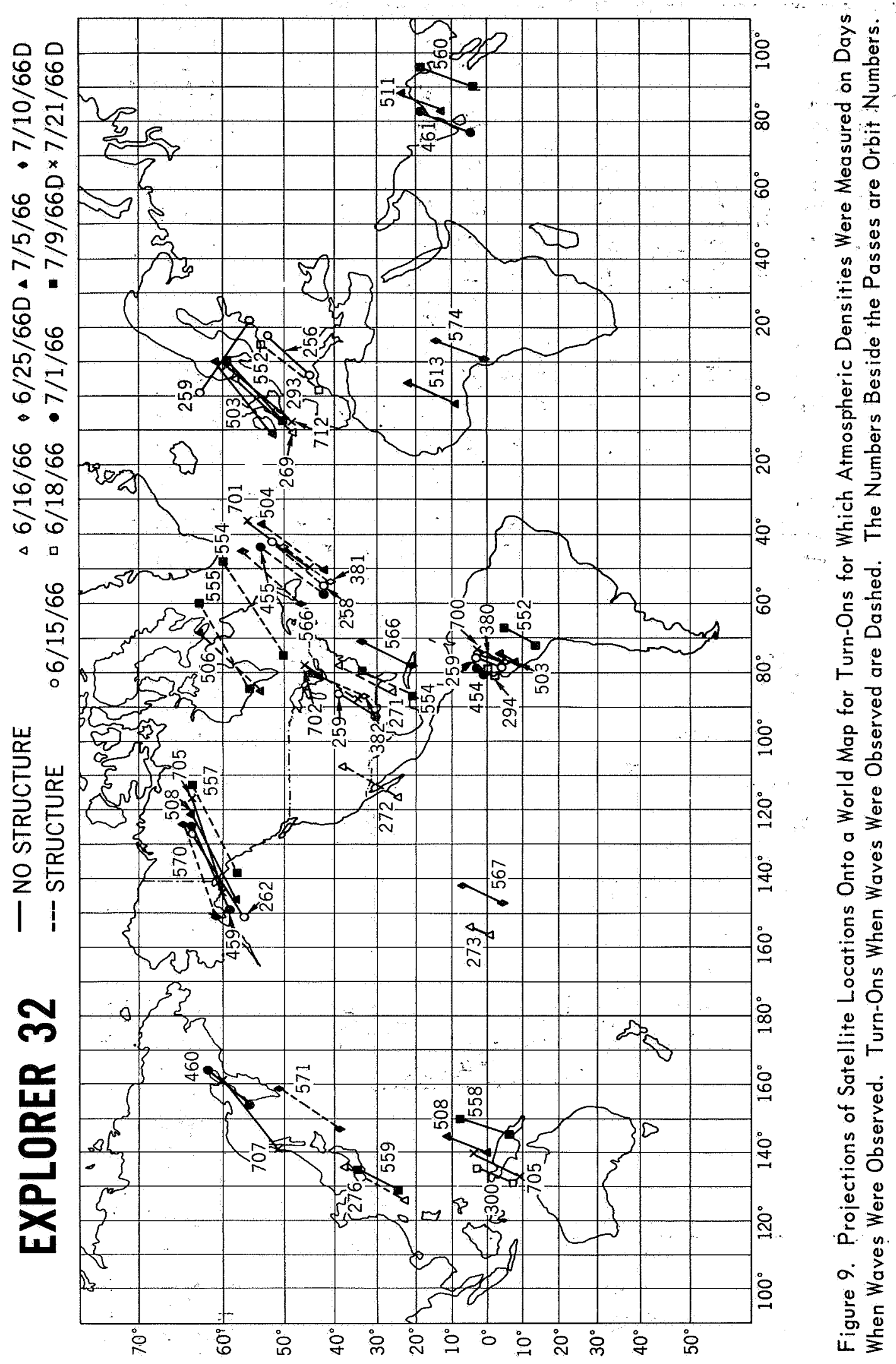




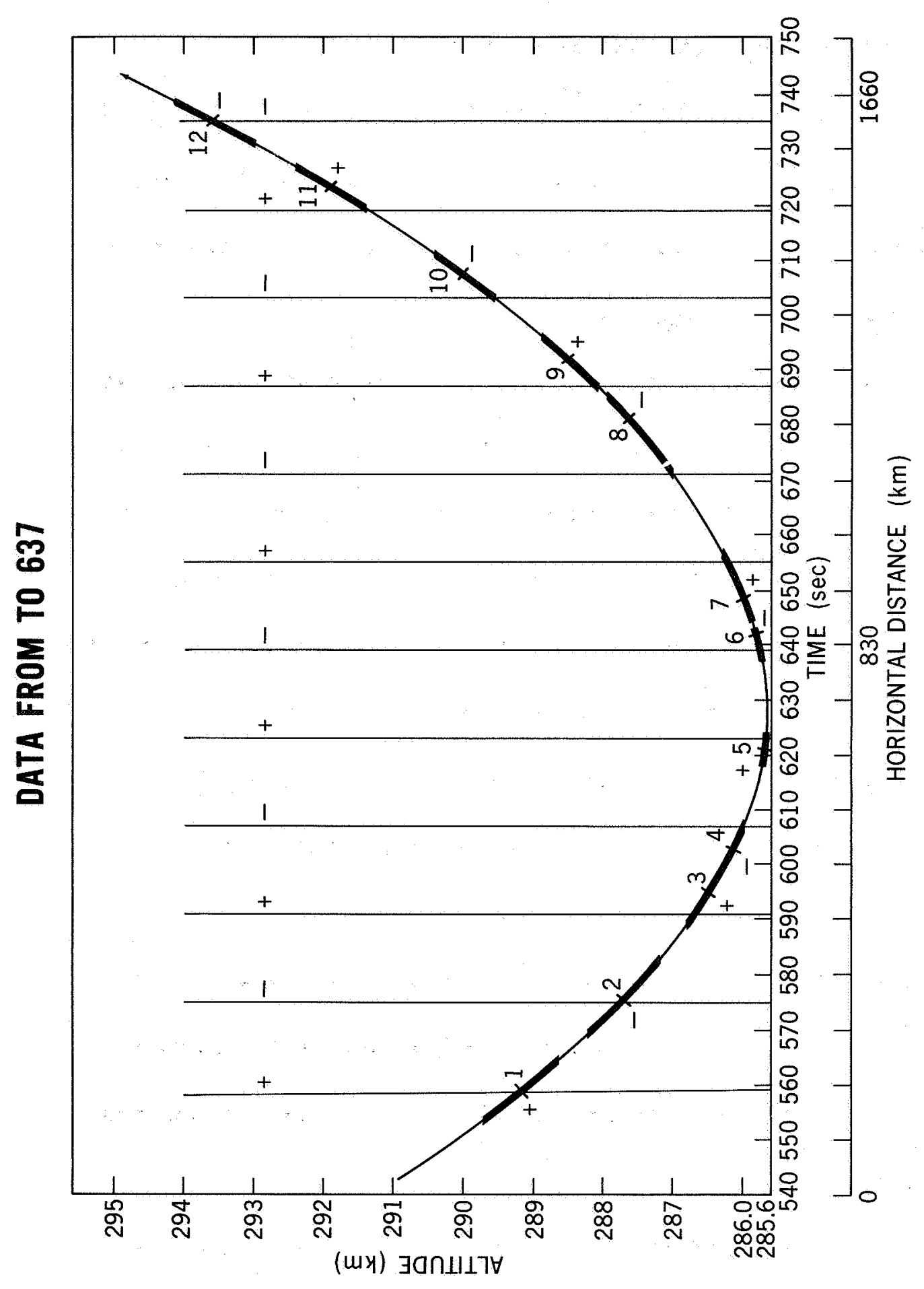

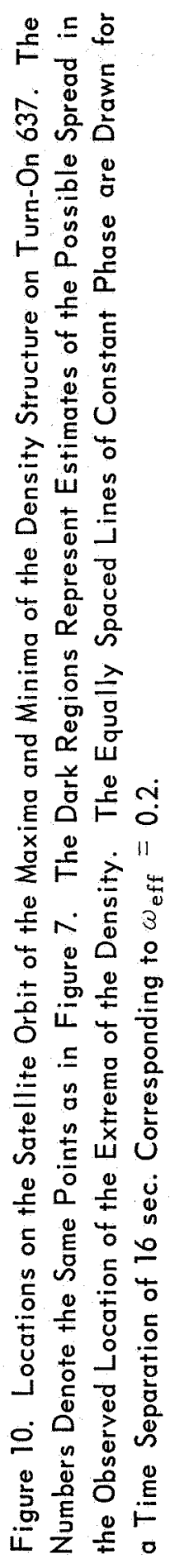

